\title{
Comparison of adverse events following immunization with pandemic influenza $A(H 1 N 1)$ pdm09 vaccine with or without adjuvant among health professionals in Rio de Janeiro, Brazil
}

\author{
José Cerbino-Neto ${ }^{1 /+}$, Ananza Tainá da Silva Santos ${ }^{1}$, Maria Isabel Fragoso da Silveira Gouvea ${ }^{1}$, \\ Renata Saraiva Pedro', Grazielle Viana Ramos', Lusiele Guaraldo', Guilherme Loureiro Werneck ${ }^{2}$ \\ ${ }^{1}$ Instituto de Pesquisa Clínica Evandro Chagas-Fiocruz, Rio de Janeiro, RJ, Brasil \\ ${ }^{2}$ Instituto de Medicina Social, Universidade do Estado do Rio de Janeiro, Rio de Janeiro, RJ, Brasil
}

\begin{abstract}
A vaccination campaign against pandemic influenza A (H1N1)pdm09 was held in Brazil in March 2010, using two types of monovalent split virus vaccines: an AS03-adjuvanted vaccine and a non-adjuvanted vaccine. We compared the reactogenicity of the vaccines in health professionals from a Clinical Research Institute in Rio de Janeiro, Brazil and there were no serious adverse events following immunization (AEFI) among the 494 subjects evaluated. The prevalence of any AEFI was higher in the ASO3-adjuvanted vaccine at $2 \mathrm{~h}$ and $24 \mathrm{~h}$ post-vaccination [prevalence ratio (PR): 2.05, confidence interval (CI) 95\%: 1.55-2.71, PR: 3.42, CI 95\%: 2.62-4.48, respectively]; however, there was no difference between the vaccines in the assessments conducted at seven and 21 days post-vaccination. The group receiving the AS03 post-adjuvanted vaccine had a higher frequency of local reactions at $2 \mathrm{~h}$ (PR: 3.01, CI 95\%: 2.12-4.29), 24 h (PR: 4.57, CI 95\%: 3.29-6.37) and seven days (PR: 6.05, CI 95\%: 2.98-12.28) post-vaccination. We concluded that the two types of vaccines caused no serious AEFI in the studied population and the adjuvanted vaccine was more reactogenic, particularly in the $24 \mathrm{~h}$ following vaccination. This behaviour must be confirmed and better characterised by longitudinal studies in the general population.
\end{abstract}

Key words: influenza A virus - H1N1 subtype - influenza vaccines - adverse effects

In April 2009, a new subtype of influenza A (H1N1) human virus of swine origin was identified in North America (CDC 2009a). This virus is also known as influenza A (H1N1)pdm09 to differentiate it from the seasonal variant. Within twoo months, the new viral subtype had met the pandemic criteria, leading the World Health Organization (WHO) to declare the existence of an influenza pandemic on 11 June 2009 (WHO 2009a). Once the new virus was recognised, vaccine development became a priority, which challenged the efficiency and coordinated responsiveness of the health industry, the scientific community and international health authorities (Girard et al. 2010). The speed with which the objective was achieved made it clear that the effort was successful. On 29 April, the virus strain A/California/7/2009 was selected as the international reference strain for manufacturing the vaccine and, five months later, on 21 September 2009, a vaccination programme was established in China (Girard et al. 2010).

In Brazil, the Ministry of Health ( $\mathrm{MOH})$ launched a vaccination campaign against influenza $\mathrm{A}(\mathrm{H} 1 \mathrm{~N} 1)$ pdm09 between 8 March-21 May 2010 (MS 2010a). The campaign used monovalent vaccines produced by three different laboratories [GlaxoSmithKline (GSK), Sanofi

+ Corresponding author: cerbino@fiocruz.br

Received 13 December 2011

Accepted 9 July 2012
Pasteur/Butantan and Novartis], which all used inactivated split-virus as the antigen and thimerosal as a preservative. The GSK vaccine was the only vaccine that also contained an adjuvant, AS03, which is composed of squalene, DL- $\alpha$ tocopherol and polysorbate 80. Although this adjuvant had been previously used in prepandemic vaccines (Leroux-Roels et al. 2007, Baras et al. 2008, Rümke et al. 2008), it was not present in any of the seasonal influenza vaccines that were used in previous campaigns. As AS03 was a new adjuvant with sparse evidence available on its safety in pregnant women, the WHO initially recommended that the first choice (when available) for this patient group should be non-adjuvanted inactivated preparations (WHO 2009b). This decision led to the contraindication of the adjuvanted vaccine for pregnant women by the MOH (MS 2010a). Given the safety concerns and the urgency to start using the vaccine on a large scale before the 2010 influenza season, the postmarketing surveillance of adverse events grew in importance in the case of the pandemic influenza vaccine, particularly for the detection of rare adverse events following immunization (AEFI), such as the recently observed cases of narcolepsy that led the European Medicines Agency to recommend restricting the use of the AS03-adjuvanted vaccine in people under age 20 (EMA 2011).

To compare the safety profile of monovalent pandemic influenza vaccines used in the 2010 campaign, we analysed the active surveillance data for adverse events that accompanied the vaccinations of health professionals from the Institute of Clinical Research Evandro Chagas (IPEC) of the Fundação Oswaldo Cruz (Fiocruz) in Rio de Janeiro (RJ), Brazil. 


\section{PATIENTS, MATERIALS AND METHODS}

The IPEC is one of the technical-scientific units of Fiocruz. Its primary activity is clinical research on infectious diseases. Along with a high complexity hospital, the IPEC has 564 professionals directly or indirectly involved in the care of patients and it is one of the reference units for the hospitalisation of influenza A (H1N1)pdm09 patients in RJ. Among its services, the IPEC offers a Reference Centre for Special Immunobiologicals (CRIE) and a Pharmacovigilance Service. CRIE investigates and treats AEFI and the Pharmacovigilance Service is part of the Sentinel Hospitals Network of the Brazilian National Sanitary Surveillance Agency (ANVISA).

For the vaccination campaign, the IPEC received two different formulations of monovalent vaccine against influenza A (H1N1)pdm09: a non-adjuvanted formulation (Sanofi Pasteur Inc, lot E7163) and an AS03-adjuvanted formulation (GlaxoSmithKline SA, lot AA03E090AA). The composition of the vaccines is shown in Table I. The availability of the two vaccine formulations varied throughout the campaign and the type of vaccine administered was determined by the availability of a given vaccine on the day that the professional sought to be vaccinated. There were no randomisations or blinding procedures during the campaign.

To identify AEFI in IPEC employees, the CRIE and the Pharmacovigilance Service implemented an active surveillance routine by telephone, which contacted the vaccinee $24 \mathrm{~h}$, seven days and 21 days post-vaccination to complete an AEFI monitoring questionnaire. In the first interview, the respondent was asked about the onset of symptoms $2 \mathrm{~h}$ and 2-24 h post-vaccination; the subsequent two interviews evaluated the symptoms experienced during the intervals between the first and second interviews and between the second and third interviews. In the objective part of the questionnaire, the respondent answered questions concerning the presence of common signs and symptoms associated with the vaccination; the respondent then had the opportunity to report any other changes that were noticed during the evaluation period. As there was no individual longitudinal follow-up that allowed the construction of a retrospective cohort, the data were analysed in a cross-sectional manner to evaluate the period and the population for each interview. The prevalence of AEFI was calculated for each interval for every professional and separately for the group receiving the non-adjuvanted vaccine and the group vaccinated with the AS03-adjuvanted formulation. The prevalence in both groups was compared by calculating the prevalence ratio (PR) of AEFI during the analysed intervals.

The reported events were classified into two types based on severity: serious reactions (leading to death, hospitalisation or permanent disability) or non-serious reactions. With respect to the clinical manifestations described in the interviews by the health professionals, the AEFI were divided into local reactions (pain, heat, erythema, oedema or induration at the vaccination site) or systemic reactions, which were defined as signs and symptoms that were temporally associated with the vaccination although they did not fit the definition of local reaction.

The data were entered into Epidata 2.2 (EpiData Association, Odense, Denmark) and the R 2.12.1 (R Foundation for Satistical Computing, Vienna, Austria) software was used for the descriptive and statistical analysis. The significance level that was chosen for all the tests was 0.05 . To check the comparability between the groups, we used Student's $t$-test for continuous variables and the chi-squared test for proportions. The PR

TABLE I

Characteristics of the healthcare professionals and vaccines in each group

\begin{tabular}{|c|c|c|c|}
\hline & & $\begin{array}{l}\text { Non-adjuvant group } \\
\qquad(\mathrm{n}=171)\end{array}$ & $\begin{array}{l}\text { Adjuvant group } \\
\qquad(\mathrm{n}=340)\end{array}$ \\
\hline \multicolumn{4}{|l|}{$\begin{array}{l}\text { Healthcare professionals } \\
\text { characteristics }\end{array}$} \\
\hline $\begin{array}{l}\text { Age (mean } \pm \text { SD) } \\
\text { (range) }\end{array}$ & & $\begin{array}{l}38.12 \pm 11.61 \\
\quad(18-62)\end{array}$ & $\begin{array}{l}37.12 \pm 11.68 \\
\quad(18-61)\end{array}$ \\
\hline \multirow[t]{2}{*}{ Gender $[\mathrm{n}(\%)]$} & Male & $57(33.33)$ & $126(37.05)$ \\
\hline & Female & $114(66.66)$ & $214(62.94)$ \\
\hline \multirow{3}{*}{$\begin{array}{l}\text { Questionnaires answered } \\
\text { per interview }[\mathrm{n}(\%)]\end{array}$} & 1 & $151(88.30)$ & $247(72.64)$ \\
\hline & 2 & $152(88.88)$ & $179(52.64)$ \\
\hline & 3 & $142(83.04)$ & $247(72.64)$ \\
\hline \multicolumn{4}{|l|}{ Characteristics of the vaccines } \\
\hline Manufacturer & & Sanofi Pasteur & GlaxoSmithKline \\
\hline Antigen & & A/California/07/2009 (H1N1) & A/California/07/2009 (H1N1) \\
\hline Adjuvant & & No & AS03 (squalene, DL- $\alpha$ tocopherol, polysorbate) \\
\hline Preservative & & Thimerosal & Thimerosal \\
\hline
\end{tabular}

$a$ : Student's $t$-test, $\mathrm{p}>0.05 ; b: \chi^{2}$ test, $\mathrm{p}>0.05$; SD: standard deviation. 
TABLE II

Number and percentage of professional in both groups with different adverse events following immunization (AEFI) in each assessment and prevalence ratio (PR) of reaction in groups vaccinated with and without adjuvant

\begin{tabular}{|c|c|c|c|c|c|}
\hline \multirow[b]{2}{*}{ Type of AEFI } & \multirow[b]{2}{*}{ Group } & \multicolumn{4}{|c|}{ Time interval evaluated } \\
\hline & & $0-2 \mathrm{~h}$ & $2-24 \mathrm{~h}$ & 1-7 days & 8-21 days \\
\hline \multirow[t]{5}{*}{ Any event $[\mathrm{n}(\%)]$} & Without adjuvant & $42(27.81)$ & $40(26.49)$ & $43(28.28)$ & $15(10.56)$ \\
\hline & With adjuvant & $141(57.08)$ & $224(90.68)$ & $58(32.40)$ & $16(6.47)$ \\
\hline & PR & 2.05 & 3.42 & 1.15 & 0.61 \\
\hline & CI 95\% & $1.55-2.71$ & $2.62-4.48$ & $0.82-1.59$ & $0.31-1.20$ \\
\hline & $\mathrm{p}$ & $<0.001$ & $<0.001$ & - & - \\
\hline \multirow[t]{5}{*}{ Local manifestations [n (\%)] } & Without adjuvant & $28(18.54)$ & $29(19.20)$ & $8(5.26)$ & 0 \\
\hline & With adjuvant & $138(55.87)$ & $217(87.85)$ & $57(31.84)$ & $2(0.8)$ \\
\hline & PR & 3.01 & 4.57 & $6.052 .98-12.28$ & - \\
\hline & CI 95\% & $2.12-4.29$ & $3.29-6.37$ & $<0.001$ & - \\
\hline & $\mathrm{p}$ & $<0.001$ & $<0.001$ & - & 0.5 \\
\hline \multirow[t]{5}{*}{ Systemic manifestations [n (\%)] } & Without adjuvant & $18(11.92)$ & $18(11.92)$ & $39(25.65)$ & $15(10.56)$ \\
\hline & With adjuvant & $16(6.47)$ & $121(48.98)$ & $47(26.25)$ & $14(5.66)$ \\
\hline & PR & 0.54 & 4.11 & 1.02 & 0.54 \\
\hline & CI 95\% & 0.291 .03 & $2.62-6.46$ & $(0.711 .47)$ & $0.27-1.08$ \\
\hline & $\mathrm{p}$ & - & $<0.001$ & - & - \\
\hline
\end{tabular}

CI: confidence interval.

and $95 \%$ confidence intervals (CI) were calculated for the AEFI groups reported in each interview. The study was approved by the IPEC Research Ethical Committee (CAAE-0021.0.009.000-11).

\section{RESULTS}

Between 8-31 March 2010, 511 healthcare workers $(90.6 \%)$ were vaccinated in the IPEC, out of a total of 564 employees, with 171 workers receiving the non-adjuvanted vaccine and 340 receiving the AS03-adjuvanted formulation. Among the vaccinated, 494 (96.67\%) responded to at least one of the adverse event interviews. The response rate for each interview ranged from $67-$ $80 \%$. Both of the vaccinated groups were comparable with respect to patient age and gender (Table I). There were no pregnant women among the evaluated healthcare professionals.

There were no reports of serious AEFI in either group. During the follow-up period, 389 (79\%) of the vaccinees reported the onset of a sign or a symptom. Compared to the group that received the non-adjuvanted vaccine, the prevalence of any AEFI $2 \mathrm{~h}$ after vaccine administration was two times greater among patients who received the AS03-adjuvanted vaccine (PR: 2.05, 95\% CI: 1.55-2.71, $\mathrm{p}<0.001)$. In the $24 \mathrm{~h}$ post-vaccination assessment, the PR was higher (PR: 3.42, 95\% CI: 2.62-4.48, p < 0.001). In later assessments conducted at seven and 21 days postvaccination, no significant difference in the occurrence of AEFI was observed between the two vaccines (Table II).

Local symptoms were the most common AEFI, particularly in the group receiving the AS03-adjuvanted vaccine, in which $55.87 \%$ of the patients reported some local reaction soon after vaccine administration and $87.85 \%$ of the patients reported a reaction $24 \mathrm{~h}$ post-vaccination. In the non-adjuvanted group, the AEFI PR $2 \mathrm{~h}$ and $24 \mathrm{~h}$ post-vaccination was 3.01 and 4.57 ( $\mathrm{p}<0.001$ ), respectively. The prevalence decreased significantly between one-seven days post-vaccination, falling to $31.84 \%$ in the group that was immunised with the adjuvant. Nevertheless, the prevalence remained significantly higher in relation to the group without adjuvant (PR: 6.05, $\mathrm{p}$ $<0.001)$. In the period between seven-21 days post-vaccination, local reactions were rare (Table II).

Systemic manifestations did not show rates as high as those observed for local manifestations, although they did increase in importance in later assessments at seven and 21 days post-vaccination. There was no neurological syndrome or immediate hypersensitivity reaction temporally associated with the vaccination. Between one-seven days post-vaccination, $25.65 \%$ and $26.25 \%$ of the patients in the groups with and without adjuvant, respectively, reported systemic reactions; the most common reactions were myalgia $(8.2 \%)$, malaise $(7.8 \%)$ and headache $(4.1 \%)$. Comparing the two groups, the greatest difference occurred $24 \mathrm{~h}$ after the vaccine administration, when the prevalence of systemic reactions in the vaccine group with adjuvant reached $48.98 \%$ and the PR was 4.11 (95\% CI: 2.62-6.46, p < 0.001). At the time of this evaluation, the most cited systemic reactions in the adjuvant group were myalgia (8\%), malaise $(7.5 \%)$, headache $(3.5 \%)$ and fever $(3.4 \%)$.

\section{DISCUSSION}

Our study identified that the presence of the AS03 adjuvant increased the vaccine's reactogenicity, mostly due to local reactions. The major contributions of this study 
are the post-marketing direct comparison between two split-virus vaccines and the quantification of the frequency of AEFI associated with the presence of the AS03 adjuvant. The observed prevalence was considerably higher and increased up to six times in the group vaccinated with adjuvanted vaccine.

Although not previously measured directly, the risk of adverse events was expected to be higher in the adjuvanted vaccine based on the safety profile of the two formulations. The first clinical studies conducted with the pandemic influenza split-virus non-adjuvanted vaccine identified adverse events with an incidence and severity similar to those observed with the same type seasonal vaccine (Vellozzi et al. 2009, MS 2010b). After using the vaccine on a larger scale, adverse events surveillance programs in the United States of America and China showed similar results (CDC 2009b, Wu et al. 2010, Liang et al. 2011). The other vaccine used in the campaign, a split-virus AS03-adjuvanted vaccine, was based on pre-pandemic vaccines against influenza A (H5N1), which had a more restricted clinical use (Baras et al. 2008, Girard et al. 2010). The studies evaluating the influenza $\mathrm{H} 5 \mathrm{~N} 1$ vaccine containing the adjuvant AS03 have associated its presence with an increase in vaccine reactogenicity (Leroux-Roels et al. 2007, Baras et al. 2008, Rümke et al. 2008) and trials conducted with the AS03-adjuvanted H1N1 pandemic vaccine also found high rates of adverse events. Local mild to moderate reactions were more common and serious adverse events were rarely reported (Carmona et al. 2010, Roman et al. 2010a, b, Waddington et al. 2010, Nicholson et al. 2011).

This study has several limitations that are typical of post-marketing surveillance studies, such as the absence of randomisation and blinding. In the assessment of distribution by gender and age, the groups were found to be comparable and the fact that the study dealt with a reasonably homogeneous population (healthcare professionals from the same hospital) might be considered a mitigating factor. Telephone follow-up for AEFI evaluations was not possible with all of the eligible subjects. This issue caused a follow-up loss of $11-47 \%$, depending on the interview (higher for the second interview). As the underlying reason for non-response was the difficulty in establishing contact and not with patient refusal to participate, we think that there is no strong reason to believe that this loss would bias the study results. Another limitation was the lack of classification of the severity of the AEFI. The outcomes that were considered serious (i.e., death, hospitalisation and permanent or temporary disability) were monitored; however, the reported signs and symptoms were not classified according to their intensity, as the interviews were made by telephone and physical examinations were not performed. Active surveillance of AEFI tends to detect milder symptoms and events with no clinical significance may have strongly influenced the reported AEFI rates. The absence of serious adverse events should be interpreted with caution because our sample size was not adequate to evaluate rare manifestations. Finally, the lack of immunogenicity data for both vaccine types precludes a risk-benefit analysis for choosing the best vaccine to be used in general practice.
Despite these limitations, this study was able to demonstrate and quantify the prevalence of AEFI associated with the presence of the AS03 adjuvant in the vaccine, which is a relevant finding for decision-making in influenza vaccination policies. If confirmed in further studies in other populations, the difference in the prevalence of adverse events observed in this study should be considered when choosing one type of vaccine over another, as the expectation of adverse events (even if not severe) is recognised as one of the factors responsible for compliance or non-compliance with a vaccination programme (Black \& Rappuoli 2010, Rubin et al. 2011). Immunogenicity and effectiveness studies must demonstrate the advantages of the AS03 adjuvanted vaccine to justify its use despite the expected associated adverse events of this vaccine formulation.

\section{REFERENCES}

Baras B, Bouveret N, Devaster JM, Fries L, Gillard P, Sanger R, Hanon $\mathrm{E} 2008$. A vaccine manufacturer's approach to address medical needs related to seasonal and pandemic influenza viruses. Influenza Other Respi Viruses 2: 251-260.

Black S, Rappuoli R 2010. A crisis of public confidence in vaccines. Sci Transl Med 2: $61 \mathrm{mrl}$.

Carmona A, Omenaca F, Tejedor JC, Merino JM, Vaman T, Dieussaert I, Gillard P, Arístegui J 2010. Immunogenicity and safety of AS03-adjuvanted 2009 influenza A H1N1 vaccine in children 6-35 months. Vaccine 28: 5837-5844.

CDC - Centers for Disease Control and Prevention 2009a. Swine Influenza A (H1N1) in two children - southern California, MarchApril 2009. MMWR Morb Mortal Wkly Rep 58: 400-402.

CDC - Centers for Disease Control and Prevention 2009b. Safety of Influenza A (H1N1) 2009 monovalent vaccines - United States, October 1-November 24 2009. MMWR Morb Mortal Wkly Rep 58: 1351-1356.

EMA - European Medicines Agency 2011. [homepage on the Internet]. [updated 2011 Jul 2011, cited 2011 Dec 21]. European Medicines Agency recommends restricting use of Pandemrix. Press release 27 July 2011. Available from: ema.europa.eu/docs/en_GB/ document_library/Press_release/2011/07/WC500109182.pdf.

Girard MP, Katz J, Pervikov Y, Palkonyay L, Kieny MP 2010. Report of the 6th meeting on the evaluation of pandemic influenza vaccines in clinical trials. Vaccine 28: 6811-6820.

Leroux-Roels I, Borkowski A, Vanwolleghem T, Dramé M, Clement F, Hons E, Devaster JM, Leroux-Roels G 2007. Antigen sparing and cross-reactive immunity with an adjuvanted $\mathrm{rH} 5 \mathrm{~N} 1$ prototype pandemic influenza vaccine: a randomised controlled trial. Lancet 370: 580-589.

Liang XF, Li L, Liu DW, Li KL, Wu WD, Zhu BP, Wang HQ, Luo HM, Cao LS, Zheng JS, Yin DP, Cao L, Wu BB, Bao HH, Xu DS, Yang WZ, Wang Y 2011. Safety of influenza A (H1N1) vaccine in postmarketing surveillance in China. $N$ Engl J Med 364: 638-647.

MS - Ministério da Saúde 2010a. [homepage on the Internet]. [updated 2010 Mar 18; cited 2011 Dec 21]. Estratégia nacional de vacinação contra o vírus influenza pandêmico (H1N1) 2009. Available from: portal.saude.gov.br/portal/arquivos/pdf/informe_tecnico_ vacina_18_03.pdf.

MS - Ministério da Saúde 2010b. [homepage on the Internet]. [updated 2010 Mar 26; cited 2011 Dec 21]. Protocolo de vigilância epidemiológica de eventos adversos pós-vacinação. Estratégia de vacinação contra o vírus influenza pandêmico (H1N1). Avail- 
able from: portal.saude.gov.br/portal/arquivos/pdf/prot_de_vig epi_e_adventos_adversos_pos_vac.pdf.

Nicholson KG, Abrams KR, Batham S, Clark TW, Hoschler K, Lim WS, Medina MJ, Nguyen-Van-Tam JS, Read RC, Warren FC, Zambon M 2011. Immunogenicity and safety of a two-dose schedule of whole-virion and AS03A-adjuvanted 2009 influenza A (H1N1) vaccines: a randomised, multicentre, age-stratified, head-to-head trial. Lancet Infect Dis 11: 91-101.

Roman F, Vaman T, Gerlach B, Markendorf A, Gillard P, Devaster JM 2010a. Immunogenicity and safety in adults of one dose of influenza A H1N1v 2009 vaccine formulated with and without AS03A-adjuvant: preliminary report of an observer-blind, randomised trial. Vaccine 28: 1740-1745.

Roman F, Vaman T, Kafeja F, Hanon E, Van Damme P 2010b. AS03(A)-adjuvanted influenza A (H1N1) 2009 vaccine for adults up to 85 years of age. Clin Infect Dis 51: 668-677.

Rubin GJ, Potts HW, Michie S 2011. Likely uptake of swine and seasonal flu vaccines among healthcare workers. A cross-sectional analysis of UK telephone survey data. Vaccine 29: 2421-2428.

Rümke HC, Bayas J-M, de Juanes J-R, Caso C, Richardus JH, Campins M, Rombo L, Duval X, Romanenko V, Schwarz TF, Fassakhov R, Abad-Santos F, von Sonnenburg F, Dramé M, Sänger R, Ballou WR 2008. Safety and reactogenicity profile of an adjuvanted $\mathrm{H} 5 \mathrm{~N} 1$ pandemic candidate vaccine in adults within a phase III safety trial. Vaccine 26: 2378-2388.
Vellozzi C, Burwen DR, Dobardzic A, Ball R, Walton K, Haber P 2009. Safety of trivalent inactivated influenza vaccines in adults: background for pandemic influenza vaccine safety monitoring. Vaccine 27: 2114-2120.

Waddington CS, Walker WT, Oeser C, Reiner A, John T, Wilkins S, Casey M, Eccleston PE, Allen RJ, Okike I, Ladhani S, Sheasby E, Hoschler K, Andrews N, Waight P, Collinson AC, Heath PT, Finn A, Faust SN, Snape MD, Miller E, Pollard AJ 2010. Safety and immunogenicity of AS03B adjuvanted split virion versus nonadjuvanted whole virion H1N1 influenza vaccine in UK children aged 6 months-12 years: open label, randomised, parallel group, multicentre study. BMJ 340: c2649.

WHO - World Health Organization 2009a. [homepage on the Internet]. [updated 2009 Jun 11; cited 2011 Dec 21]. World now at the start of 2009 influenza pandemic. Statement to the press by WHO Director-General Dr Margaret Chan. Available from: who.int/ mediacentre/influenzaAH1N1_presstranscript_20090611.pdf.

WHO - World Health Organization 2009b. Strategic advisory group of experts on immunization - report of the extraordinary meeting on the influenza A (H1N1) 2009 pandemic, 7 July 2009. Wkly Epidemiol Rec 84: 301-304.

Wu J, Xu F, Lu L, Lu M, Miao L, Gao T, Ji W, Suo L, Liu D, Ma R, Yu R, Zhangzhu J, Liu W, Zang Y, Li X, Zhang X, Pang X, Deng Y 2010. Safety and effectiveness of a 2009 H1N1 vaccine in Beijing. N Engl J Med 363: 2416-2423. 